\title{
A crítica teatral de Sábato Magaldi
}

João Roberto Faria

自 PRECISO saudar com entusiasmo a publicação de Amor ao teatro (Edições Sesc), de Sábato Magaldi. O livro, organizado por Edla Van Steen, reúne, em suas impressionantes 1.224 páginas, 783 textos críticos, escritos para o Jornal da Tarde entre 1966 e 1988. Durante 22 anos, Sábato foi crítico teatral desse jornal paulista, no qual deixou registrada a história cênica de um período marcado por importantes inovações estéticas de artistas, dramaturgos e encenadores, porém assombrado pelos desmandos da ditadura militar e aliviado em seguida pela redemocratização do país.

Ainda que seja impossível, no espaço de uma resenha, dar conta de todo o conteúdo de um livro tão rico em informações e reflexões, creio que posso ressaltar suas qualidades, a começar pelas características dos textos críticos, construídos com elegância estilística, conhecimento profundo da matéria e largueza de visão. Sábato se guiava por alguns princípios, que deixou estabelecidos no artigo "Sobre a crítica" (Teatro em foco. São Paulo: Perspectiva, 2008). A seu ver, a primeira preocupação do crítico teatral deve ser a de detectar a proposta do espetáculo e julgar se ela foi bem realizada, levando em conta o trabalho de todos os envolvidos na montagem: o diretor, os intérpretes, o dramaturgo, o cenógrafo, o figurinista etc. Ele exige do crítico que saiba escrever, que seja claro, objetivo e honesto, sem qualquer tipo de preconceito. E que seja culto, que conheça a história do teatro universal e do teatro brasileiro, que estude para que seus julgamentos tenham autoridade. Sábato defende ainda um comportamento ético para o crítico, que não se deve deixar levar por amizades, inimizades ou mesmo pelo mau humor. Até um comentário mais duro pode ser feito com respeito e comedimento, ele afirma, para concluir: "É que julgo o amor pelo teatro e a boa fé as qualidades primeiras da função de crítico".

Eis aí a fonte do título do livro, que indica não apenas um sentimento, mas um compromisso e uma postura diante do espetáculo teatral. "Sobre a crítica", de Sábato, lembra "O ideal do crítico", de Machado de Assis: ambos os textos discorrem sobre uma atividade intelectual que deve estar nas mãos de pessoas preparadas, que saibam de sua importância na vida cultural de uma nação.

Sábato iniciou sua carreira muito cedo, aos 22 anos, no Rio de Janeiro, nas páginas do Diário Carioca. De junho de 1950 a setembro de 1953, escreveu algumas dezenas de textos, nos quais se posicionou firmemente a favor da modernização do teatro brasileiro, desferindo críticas contundentes aos "mestres do passado" e elogiando as peças modernas de autores estrangeiros e brasileiros. Já nesses anos faz a defesa de Nelson Rodrigues, que sofria ataques da crítica moralista e conservadora, ressaltando o papel revolucionário que o dramaturgo vinha desempenhando desde a estreia de Vestido de noiva, em 1943. A produção crítica desse período, que valoriza as encenações modernas e a figura do encenador, como responsável pela unidade artística do espetáculo teatral, foi parcialmente transcrita no livro Sába- 
to Magaldi e as heresias do teatro (Perspectiva, 2012), de Maria de Fátima da Silva Assunção.

Uma temporada na França, onde fez estudos sobre teatro e estética, seguiu-se à atividade crítica no Diário Carioca. De volta ao Brasil, Sábato mudou-se para São Paulo, aceitando o convite de Alfredo Mesquita para lecionar a disciplina "Teatro Brasileiro", na Escola de Arte Dramática. Em 1956, começou sua colaboração com o "Suplemento Literário" do jornal O Estado de S. Paulo, que se estendeu por mais de dez anos, nos quais escreveu sobre dezenas de dramaturgos, brasileiros e estrangeiros. Trabalhando ao lado de Décio de Almeida Prado, diretor do "Suplemento" e crítico teatral do jornal, Sábato dedicava-se ao noticiário, redigindo textos mais longos, nos quais preparava o público para assistir a um espetáculo, por meio da análise e interpretação da obra de um determinado autor. Essa atividade foi fundamental para o seu amadurecimento intelectual, pois lhe exigiu muito estudo para escrever sobre os trágicos gregos, Shakespeare e Molière, ou sobre autores modernos como Brecht, O’Neill, Pirandello, Sartre, Beckett, entre tantos outros, como se vê no livro O texto no teatro (Perspectiva, 1989). Ao mesmo tempo, como professor de Teatro Brasileiro, especializou-se na matéria e de suas pesquisas e reflexões nasceu o imprescindível Panorama do teatro brasileiro, em 1962, publicado pela Difel.

Ao assumir a coluna de crítica teatral do Jornal da Tarde, em 1966, Sábato estava preparadíssimo para dar conta do trabalho que tinha pela frente. Conhecia as correntes estéticas do passado e do presente, bem como as obras dos principais dramaturgos brasileiros e es- trangeiros e era espectador assíduo dos espetáculos em cartaz.

Em Amor ao teatro, percebe-se já nos primeiros textos o crítico experiente e maduro, capaz de avaliar as qualidades e defeitos de montagens importantes do Grupo Oficina e do Teatro de Arena, e de encenadores como José Renato, Antunes Filho, Gianni Ratto, Ademar Guerra, Jairo Arco e Flexa, Amir Haddad, Fauzi Arap e Antônio Abujamra, entre outros, ou de reconhecer o talento de um dramaturgo estreante, como Plínio Marcos, afirmando sobre Navalba na carne: "A literatura teatral brasileira nunca produziu uma peça de verdade tão funda, de calor tão autêntico, de desnudamento tão cru da miséria humana". Na segunda metade dos anos 1960, Sábato testemunhou a aclimatação do teatro épico de Brecht entre nós, comentando não apenas as encenações de suas peças, mas também a apropriação de suas ideias por parte de Augusto Boal ao criar o "Sistema Coringa" e escrever com Guarnieri Arena conta Zumbi e Arena conta Tiradentes. Também mereceu registro a crise do teatro político, a partir da encenação de $O$ rei da vela, de Oswald de Andrade, dirigida por José Celso Martinez Corrêa no Oficina. Os espetáculos de vanguarda de Victor Garcia surpreenderam o crítico, que ressaltou a inventividade do encenador em seu diálogo com Artaud, afirmando sobre Cemitério dos automóveis: "O ritual artaudiano aí está, no seu melhor delírio de imaginação, para se abrir numa teatralidade ampla, contestando as fórmulas e os processos tradicionais". O final da década reservou ainda uma surpresa agradável, que Sábato registrou com satisfação: o florescimento de uma nova dramaturgia brasileira, que soube 


\section{$A M \bigcirc R$ \\ SÁ B ATO \\ $A O$ \\ MAGALDI \\ TEATRO \\ Sesce}

MAGALDI, S. Amor ao teatro - Sábato Magaldi. Org. Edla Van Steen.

São Paulo: Sesc (Livros), 2015. 1224p. (Col. Sesc Críticas).

captar o clima de sufoco imposto ao país, por meio da análise de indivíduos em choque com a realidade e consigo mesmos. Vale a pena ler em conjunto os comentários críticos sobre $O$ assalto, de José Vicente; Fala baixo, senão eu grito, de Leilah Assumpção; Cordélia Brasil, de Antônio Bivar, À flor da pele, de Consuelo de Castro, e As moças, de Isabel Câmara. A esses jovens autores vieram se juntar outros que ficaram conhecidos como a "geração 69", cuja qualidade foi atestada por vários estudiosos, entre eles Anatol Rosenfeld.

$O$ recrudescimento da censura, a partir do AI-5, trouxe prejuízos imensos para o nosso teatro. Durante o governo Médici, o número de espetáculos cortados ou impedidos integralmente de subir à cena foi muito grande. No final de 1971, Sábato observou que as peças brasileiras não podiam fazer uma crítica contundente dos problemas enfrentados pelo país: "Dramaturgos e encenadores de talento, pressionados pelas circunstâncias, estão jogando com as armas que lhes permitem utilizar. Está claro que ninguém se sente realizado por inteiro, embora procure afirmar-se com a maior dignidade artística". Além da censura, a perseguição a artistas, dramaturgos e encenadores resultou em prisões, humilhações, a morte da diretora Heleny Guariba e o exílio de Augusto Boal e José Celso Martinez Corrêa, que provocou o esfacelamento do Teatro de Arena e do Grupo Oficina. É com tristeza que acompanhamos esse período sombrio da nossa história teatral, cujo início praticamente coincidiu com a morte da atriz que era símbolo da resistência cultural entre nós. Em uma das récitas de Esperando Godot, de Samuel Beckett, com direção de Flávio Rangel, Cacilda Becker teve um aneurisma e faleceu alguns dias depois. Sábato, em sua crítica datada de 10 de abril de 1969, havia escrito sobre o desempenho dela: "A figura frágil, desajeitada, chapliniana, com a máscara clownesca, ilumina-se de uma vida interior e uma sabedoria que fazem de Estragon talvez o ponto mais alto da carreira de Cacilda e uma criação antológica em nosso palco". As palavras do crítico devem ter sido lembradas por todos que prantearam nossa maior atriz; hoje, atestam sua sensibilidade em relação ao trabalho dos intérpretes. Aliás, já é tempo de assinalar mais essa característica de suas críticas: o espaço reservado para comentar as atuações dos artistas. Como são centenas, para não cometer injustiças e citar apenas alguns, asseguro que em Amor ao teatro todos os nossos principais intérpretes do período abarcado pelo livro são contemplados com um comentário sobre seus desempenhos. Há 


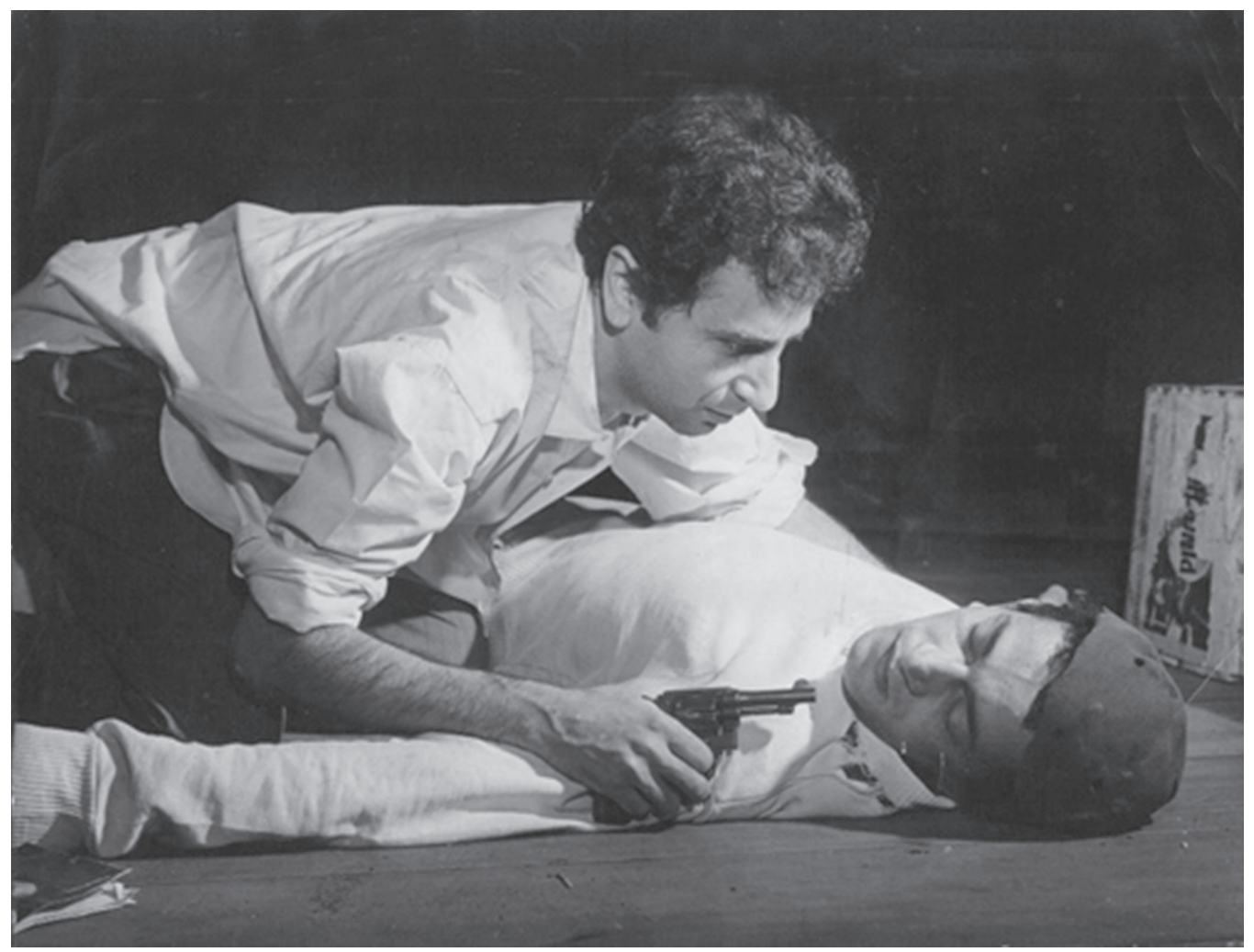

Cena de "Dois perdidos numa noite suja", de Plínio Marcos.

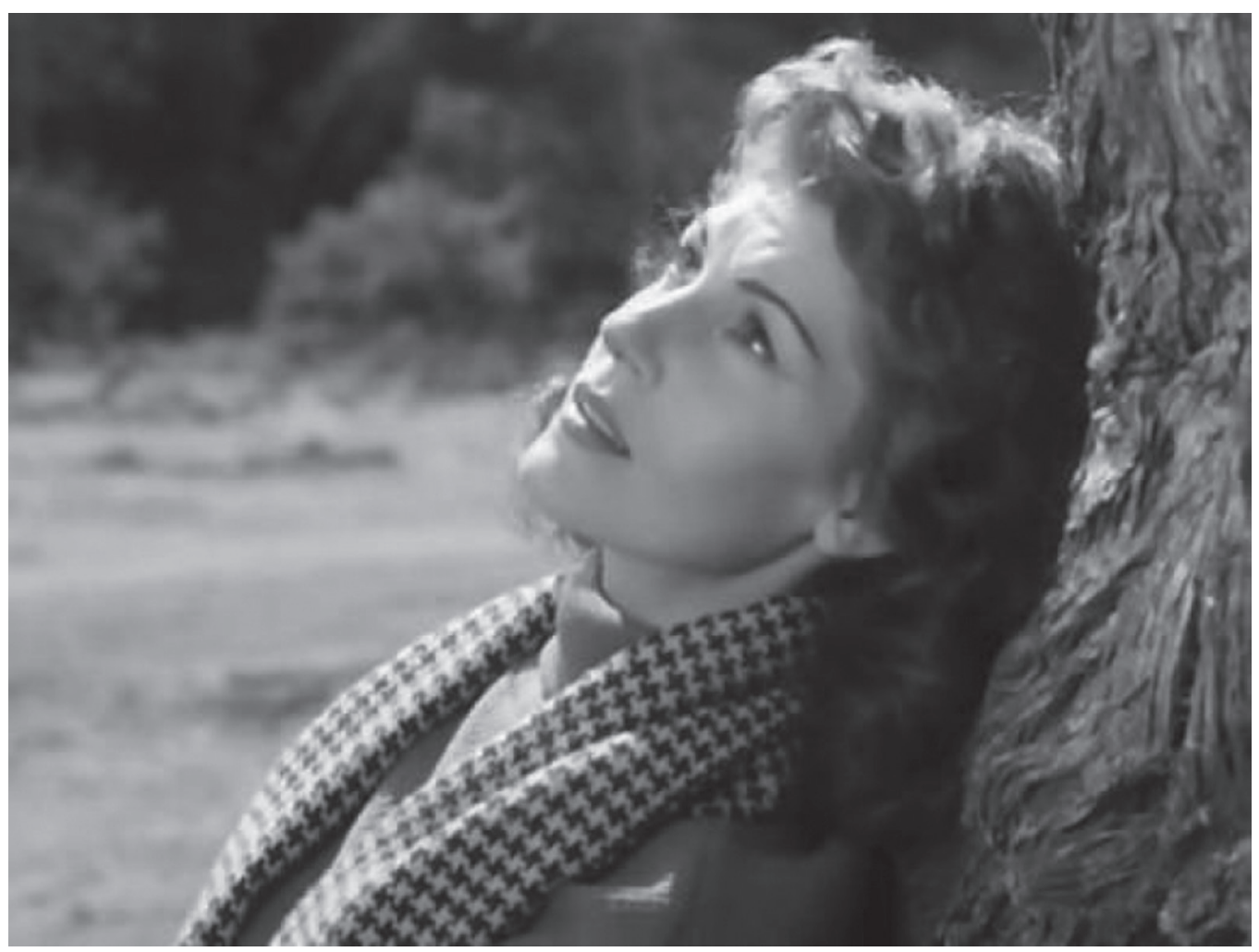

A atriz Cacilda Becker no filme "Floradas na serra" (1954). 
dois textos de 1971 que se destacam, por apresentar os artistas jovens que vêm se revelando: "Atrizes brasileiras" e "Atores brasileiros". A mesma atenção é dada ao trabalho dos cenógrafos, figurinistas e demais profissionais, uma vez que os textos críticos de Sábato apreendem o espetáculo como uma totalidade.

À medida que avançamos na leitura do livro, vamos deparando com questões que hoje são discutidas já a partir de uma perspectiva histórica, como a divisão, nos “anos de chumbo", entre grupos e encenadores que optaram pelo irracionalismo, pela contracultura, pela expressão corporal, e os que se mantiveram no terreno do racionalismo, para se contrapor à dura realidade do país. Surgem novas tendências, como a criação coletiva, de grupos teatrais alternativos, formados por jovens que não se interessam pelo teatro de cunho político. A partir de meados da década de 1970, com a abertura "lenta e gradual" do general Geisel, o teatro brasileiro avança na crítica à ditadura e espetáculos marcantes são comentados por Sábato, com destaque para a bela peça Ponto de partida, de Guarnieri - que evoca em cena o assassinato de Wladimir Herzog pela repressão; $O$ último carro, de João das Neves; e Gota d’água, de Chico Buarque e Paulo Pontes. Eis como ele inicia a crítica a Murro em ponta de faca, de Augusto Boal, em outubro de 1978: “A abertura política registrada nos últimos meses $\log$ o se refletiu no teatro. Se a dramaturgia brasileira chegava pouco ao palco, pela severidade da censura, bastou a liberalização relativa do regime para o teatro dar um incrível salto".

De fato, no final da década de 1970 e início da seguinte a dramaturgia brasileira reconquista um espaço importante nos palcos paulistas. Alguns dramaturgos dão continuidade à crítica da ditadura, em textos vigorosos como Patética, de João Ribeiro Chaves Neto - que explicita o que ficara implícito em Ponto de partida; e Rasga coração, de Oduvaldo Vianna Filho, entre outros. É claro que há montagens importantes de peças estrangeiras nesses anos, mas o que chama a atenção nas críticas de Sábato é o surgimento de vários dramaturgos talentosos, como Maria Adelaide Amaral, Naum Alves de Souza, Luís Alberto de Abreu, Alcides Nogueira e Flávio de Souza, para citar os que são mais encenados. Também se destacam alguns jovens encenadores, como Márcio Aurélio, Luiz Antônio Martinez Corrêa, Ulysses Cruz, José Possi Neto, Cacá Rosset, Roberto Lage, Eduardo Tolentino, Jorge Takla, Luiz Roberto Galizia e José Rubens Siqueira. O grande acontecimento teatral do final da década de 1970, no entanto, foi a montagem de Macunaima, pelo Grupo de Arte Pau Brasil, com direção de Antunes Filho. Sábato aponta em sua análise a importância do espetáculo para o seu encenador, que deixava para trás "os recursos de um competente profissionalismo, em favor de um experimentalismo sadio e generoso". Esse novo caminho de Antunes teve continuidade com outros espetáculos importantes como Nelson Rodrigues, o eterno retorno - e, como se sabe, foi trilhado por vários encenadores na década de 1980, que procuraram se nutrir do mesmo espírito de pesquisa e experimentação em montagens de inquestionável beleza plástica e apuro técnico.

Haveria muito ainda a dizer sobre Amor ao teatro. Procurei destacar o que me pareceu importante para se conhecer a excelência do crítico teatral e para 
reconhecer o livro como uma referência fundamental para o estudo e conhecimento do teatro brasileiro moderno. Louvo as Edições Sesc pela iniciativa de publicar essa coletânea de textos críticos. Trata-se de uma obra há muito tempo esperada pelos leitores e admiradores de Sábato Magaldi.

João Roberto Faria é professor da Faculdade de Filosofia, Letras e Ciências Humanas da Universidade de São Paulo (FFLCH-USP). @ - jgfaria@uol.com.br

${ }^{I}$ Faculdade de Filosofia, Letras e Ciências Humanas, Universidade de São Paulo, São Paulo/SP, Brasil. 